\title{
CONCEPTUAL CHALLENGES IN UNDERSTANDING INNOVATIVE EDUCATION IN ORGANIZATIONAL CONTEXT
}

Dr. Mikhail Klarin, Laboratory for Didactics (General Theory of Education), Institute for Strategy of Education Development, Russian Academy of Education, Moscow, Russian Federation

E-mail: consult@klarin.ru

ARTICLE INFO

Studies and Articles

Received: May, 20.2016.

Revised: June, 05.2016.

Accepted: June, 08.2016.

doi:10.5937/IJCRSEE1601067K

UDK

374.7

37.013 .83

Keywords:

adult and continuing education,

innovative education,

collective learner,

transformative education.
A B S T R A C T

The paper suggests shifts in educational thinking about adult and continuing education practices including: goal setting, nature of the learner, character of education, and its elements including the sources in the educational process, evaluation of its outcomes, and social (micro-social) role of education.

The author explores innovative vs. conventional adult learning, and introduces several new approaches to adult education. Several conceptual challenges (paradoxes) are considered that do not fit the traditional educationalist's thinking. The conceptual shifts are explored as cognitive gaps, leading to insights about the nature of adult education, and pragmatic changes in shaping education to transform individual and collective experience.

\section{INTRODUCTION}

We look at learning as act or process of acquiring new, or modifying the existing experience, including knowledge, skills, values, and/or preferences. Education is seen as a process aimed at supporting/facilitating learning. Features of adult and continuing education are defined by the nature of adults as learners. An essential part of adult learning is based on personal experiences which have innovative/ transformative nature.

Adult Learning as Transformation of Experience. Adult learning as a means of restructuring experience implies transformations, or shifts in individual and/or collective meanings. Transformation of experience and meanings correlate with situations of change and/or crisis in individual or collective learners' lives, or activity modes. Therefore, genuine learning and effective education is closely

Corresponding Author

Dr. Mikhail Klarin, Laboratory for Didactics (General Theory of Education), Institute for Strategy of Education Development, Russian Academy of Education, Moscow, Russian Federation

E-mail: consult@klarin.ru

\section{(i)}

This work is licensed under a Creative Commons Attribution 4.0 International license. The article is published with Open Access at www.ijcrsee.com
C) 2016 IJCRSEE. All rights reserved.

related to life crisis situations and/or crises in the workplace. Typical examples of the latter include: role adaptation crisis, job routine crisis, long tenure crisis. M. V. Klarin (Кларин, M. B., 2016) adds crises of professional dynamics including: role change, job function redesign, crises of work team development stages., situation of an organization going through M \& A, strategy change, downsizing, etc.

Adult education process is based on development of new experience, and its further transformation. Of course, in educational practice experience is always being shaped. However, in the conventional learning prevailing focus is on shaping experience from zero. In innovative adult education, the focus is restructuring experience. Pragmatically speaking, the transformational nature of education calls for the use of reflective educational practices (reflective, interactive learning, action learning, coaching).

From the learning perspective the crisis situation of organizational restructuring involves teams, departments, or whole companies, i.e. collective entities acting as learners whose experience undergoes drastic restructuring. Relevant experience change, however, is not considered subject of deliberate arrangement of learning new experience, i.e. education. 


\section{INNOVATIVE PRACTICES IN ADULT EDUCATION}

In a meta-study of adult and continuing education (Кларин, М. В., 2014) we have outlined a number changes in innovative vs conventional education practices: a) goal setting, b) character of the learner, c) nature of education, d) the sources of learning in the educational process, e) evaluation, f) social (microsocial) nature of learning.

a) Conceptual shift in goal-setting implies a shift from "academic" design of outcomes (e.g. mastering KSA's - knowledge, skill, and abilities) to outcomes in the job contexts, including management outcomes.

b) Conceptual shift in understanding of the learner implies a shift from an image a person with of zero relevant experience to an experience-loaded adult whose prior experience matters, as may heavily influence a newly acquired experience. Another shift is taking into account not only individual, but also collective learners.

c) Conceptual shift in understanding the nature of education: implies a shift from gaining knowledge to transforming experience and/or environment.

d) Conceptual shift in the sources of new experience in the educational process includes shifts from information sources to real life/work experience (the 70/20/10 rule).

e) Conceptual shift in evaluation includes departure from evaluating knowledge and skills to evaluating behavior/competency changes, real job behaviors, of business performance, and return on investment.

f) Conceptual shift in understanding the nature of learning includes departing from maintenance learning to innovative learning (Botkin, J. W., Elmandjra, M. and Malitza, M., 2014). We can interpret this as shifting the focus from transfer of culture to creating new cultural experience.

Conceptual shifts in understanding of both individual and collective experience are supported and/or provoked by innovative education practices.

What is new experience? When the components of culture, or social experience is transferred, we deal with known experience. Its possible novelty for the learners may be introduced in artificial, "pedagogical" purposes. However, "the teacher knows the right answer". Acquiring new experiences in the process of learning when no right answer is known is adding accumulated, reflected and structured experience to the collective experi- ence, i.e. the culture. The traditional concept of education implies transfer of the "whole body of culture' to the learners (Kraevskij, V. V. and Lerner, I. Y., 1984). Nowadays, in many situations where learning is involved, there are no patterns of experience ready to be presented, explained, or taught. The idea of taking long time to adapt pieces of experience for educational transfer often becomes obsolete (Кларин, М. В., 2014).

Innovative Learning and Innovative Education. In innovative education we deal with a very special nature of the educational process, i.e. new experience is obtained mastering in the process of its generation. Innovative, transformative learning intentionally builds new professional experience in the process of experience transformation. In situations of organizational change, a special type of learning for a collective entity is taking place, i.e. transformative education.

\section{Collective Learning and Collective}

Learner. Modern educational practices call for special attention to the concept of collective learner. So far, research and studies of non-individual learning were focused on cooperative, or collaborative learning, in which two or more individuals learn together. Some authors look at cooperative learning as a mild form of unity, in which individuals take responsibility for a separate pieces or perspectives of learning, and then bring their respective parts together, whereas collaborative learning implies a stronger mutual engagement of all participants in a group effort, and a coordinated effort to solve the problem. P. Dillenbourg (Dillenbourg, P., 1999) argued that collaborative learning is characterized by symmetry, shared goals and working. We define collective learner as a collective actor in a shared learning process in which joint learning outcome is actively produced (rather than passively received).

Organizational Learning as Collective Learning. What learning outcome is obtained in organizational learning from the organizational standpoint? Companies do not always think in terms of education or put people development in the focus of their attention. For an organization learning is a means to keep up its 'dynamic capabilities', i.e. abilities which allow the company master and routinize actions aimed at the development and adaptation of operational routines, which ensure the effectiveness of the organization.

M. Zollo and S. G. Winter defined a dynamic capability as a learned structured pattern of collective activity by which the organi- 
zation systematically generates and modifies its operating routines in pursuit of improved effectiveness. Dynamic capabilities allow the organization to flexibly manage, change and transform its operational routines in a changing environment. An important aspect of routines is the tacit knowledge. As different from competencies, knowledge, or skills, it can hardly be clearly shaped and/or formulated. M. Zollo, and S. G. Winter argued that general organizational learning mechanisms for gaining dynamic capabilities (organizational learning) include: experience accumulation, knowledge articulation, and knowledge codification. As they describe the dynamic capability-building process: "Dynamic capabilities emerge from the coevolution of tacit experience accumulation processes with explicit knowledge articulation and codification activities" (Zollo, M. and Winter, S. G., 2002). The research on dynamic capability-building process also gives insight into what can be done to deliberately 'educate', or rather develop the organization as a collective learner. When designing the organizational learning the focus is primarily on eliciting the tacit knowledge.

Successful organizational learning includes creating new experience, and a retrospective reflection of the generation process. Typical formats include specially arranged facilitation sessions. General approach to collective learning is based on the Kolb's cycle. In present author's consulting experience retrospective analysis works as a "sublimation" or "second order" of Kolb's cycle.

Cycle Models of Collective Learning. $P$. M. Senge suggested understanding of organizational learning that implies a collective ability to systematically achieve the results desired by the members of the group (Senge, P. M., 1990). Cycle type of models are used to describe and design organizational learning. E.g., D. Garvin (Garvin, D. A., 2003) breaks organizational learning in stages: a) gathering information, 2) information processing, 3) application. Organizations often use Deming's model: PDCA model (Plan - Do - CheckAct). Organizational learning programs are often planned so that a team rather than an individual employee becomes the learner. J. Pfeffer and R. I. Sutton (Pfeffer, J. and Sutton, R. I., 2000) argued that in corporate development programs priorities are shifted from individual to collective/institutional results; they note that it is the use of knowledge in the practical activity that defines the difference between successful and unsuccessful learning of an organization (as a collective learner).
Tacit Knowledge. Experience to be transferred often includes 'implicit' or 'tacit' knowledge, the part of human experience which can hardly be clearly articulated and reflected on. The concept of tacit (personal, or silent) knowledge was coined by M. Polanyi (Polanyi, M., 1967). A well-known example of tacit knowledge is riding a bicycle: a person who can do it is unable to pass on their knowledge. A talented teacher may not be able to describe the way in which he comes to their impromptu decisions, transforming the course of training. Similarly, in professional performance full description and transfer of the whole set of actions is not always possible.

In recent years, the interest of experts is drawn to tacit knowledge, which is often undetected basis for high efficiency, and/or (in the case of commercial companies) the basis for sustainable competitive advantage in the marketplace. Management experts willingly quote the former Hewlett Packard CEO Lew Platt: «If only HP knew what HP know, we would be three times more productive".

\section{A CASE FOR ADULT EDUCATION IN CORPORATE CONTEXT}

In the corporate context education is seen as a process, and a special effort to arrange learning in corporate environment to achieve learning outcomes relevant both for individuals, and the organization.

Phases of Transformative Education. M. V. Klarin (Кларин, М. В., 2015) suggested four general phases of transformative education in an organization: Adopt - Adapt - Transform - Transfer.

Adopting Collective Experience. The desired learning/educational outcome is adopted work experience. The challenge for the Organization is to master the new experience by teams of employees (including managers) in order to improve performance of teams, individuals, and/ or organization as a whole. The challenge for collective learners is to master the new professional experience presented in an 'expert', normative way. The challenge for a facilitator is to present professional experience to be adopted by participants who are learning by mastering presented models.

Adapting collective experience. The desired learning/educational outcome is adapted work experience (i.e. modified experience, with its structure unchanged). The challenge for the Organization is: to adapt the experience 
of professional activity based on the proposals by employees to improve the work of a department or the Organization as a whole. The challenge for the collective learner is to learn and adapt presented normative/model experience of professional activity to the conditions of their own activities. The challenge for the facilitator is to lead the process of adapting the new experience.

Transforming Collective Experience. The desired learning/educational outcome is transformed, i.e. restructured work experience. The challenge for the organization: to create new work experience (usually due to the experience of external experts, consultants), build and transfer new professional experience (including management) across the organization, transforming the work of a department or the organization as a whole. The challenge for the collective learner is: generate new professional experience. The challenge for the facilitator is to lead the transformation process, transforming the experience of the participants. Participants develop professional norms/standards in the context of their activities and plan how to realize their standards.

Transferring Collective Experience. The desired learning/educational outcome is ability and implementation of transferring work experience. The challenge for the organization is: to transfer/transmit new experience to reshape the work of a department or the organization as a whole. The challenge for the collective learner is: to create procedure of transferring new professional experience, transfer it, involving next groups of employees in the process of adopting, adapting, enriching, and transmitting new experience in a department or the whole organization. The challenge for collective learner is: to transfer new professional activities to other staff, performing a training role. The challenge for the facilitator is to support the process of transferring the new experience.

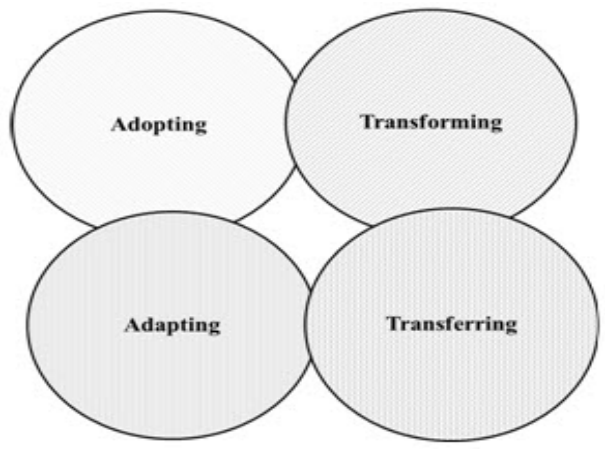
ucation

Figure 1. Phases of Transformative Ed-

\section{PARADOXES OF ADULT EDUCATION}

In adult education practice we may find paradoxes that do not fit the traditional educationalist's thinking. I treat paradoxes as cognitive conflicts, cues alerting our thinking in its proper sense, as a thorough exploration of the subject of the paradox.

Thus for exploratory pedagogical thinking paradoxes emerge as conceptual challenges indicating gaps between the phenomena of educational reality and familiar ways to describe this reality. Changes in understanding will be followed by relevant practical/pragmatic changes of educational practices.

The Paradox of Non-Academic Nature of Learning. In corporate learning practice, education becomes an integral part of human resource development. As a result, there is a contradiction between the "academic" nature of goal-setting (e.g., in terms of knowledge, skills and abilities) and managerial nature of the expected learning outcomes (changes of competencies, work activities, job performance, new performance outcomes of teams, departments, or the organization as a whole).

This paradox challenges the traditional pedagogical thinking. A response to this challenge we see in conceptual transformation of pedagogical thinking, and a pragmatic shift of educational goal setting to a coherent process of generating, recording, and developing of new cultural experiences. This paradox leads to paradoxes of non-academic learning goals and non-academic evaluation of learning outcomes.

These paradoxes challenge the conventional ideas of the learners' role in the process of education. I see the response to these challenges in conceptual change of educational mentality, and relevant pragmatic changes: (1) in conscious planning of non-academic transformative interactions in learning; (2) in a special design including internal, personal gaps in upfront design of the learning/educating process.

A Conceptual Challenge / Paradox of Non-Expert Facilitator Role. In corporate learning there is often a situation where the 'educator' (trainer, consultant) has the role of facilitator, guiding the learner generation of subjectively and objectively new experience. Here arises the paradox of expertise: the facilitator has no advantages over learners as related to the subject knowledge, his task is to arrange and facilitate a productive discussion leading to generation of new experiences. 


\section{IMPLICATIONS OF THE CONCEPTUAL CHALLENGES}

These conceptual challenges contradict the conventional ideal of education that transfers the content, and the role of educator/ trainer as a subject area guide. The response to this challenge is revising beliefs about the nature and essence of the educator's role, and pragmatic shifts in the use of their expertise in education. Their expertise is expected to be primarily focused on facilitating the process of learning, and moderately focused on the content.

To build innovative learning practices, we need to make more extensive use of conceptual and practical tools of educational process design with focus on developing and transforming individual and collective experience.

\section{Conflict of interests}

The author declares no conflict of interest.

\section{REFERENCES}

Botkin, J. W., Elmandjra, M., \& Malitza, M. (2014). No Limits to Learning: Bridging the Human Gap: The Report to the Club of Rome. Elsevier.

Dillenbourg, P. (1999). What do you mean by collaborative learning.Collaborative-learning: Cognitive and computational approaches, 1, 1-15.

Garvin, D. A. (2003). Learning in action: A guide to putting the learning organization to work. Harvard Business Review Press.

Кларин, М. В. (2016, in press). Инновационнье модели обучения: исследование мирового onbıта. Монография. Москва, Луч. (in Russian).

Кларин, М. В. (2015). Инновационное обучение в образовании взрослых. Проблемы современного образования. Интернетжурнал, 4, 5-27. (in Russian).

Кларин, М. В. (2014). Инновационное образование: дидактический анализ. Педагогика. 6, 32-39. (in Russian).

Knowles, M. S. (1984). Andragogy in action (pp. 1-21). San Francisco: Jossey-Bass.

Kraevskij, V. V., \& Lerner, I. Y. (1984). The Theory of Curriculum Content in the USSR. United Nations Educational, Scientific and Cultural Organization, 7, place de Fontenoy, 75700 Paris, France.

Pfeffer, J., \& Sutton, R. I. (2000). The knowing-doing gap: how smart companies turn knowledge into action. Organizational Dynamics, 1(29), 76-77.

Polanyi, M. (1967). The tacit dimension. London: Routledge.

Senge, P. M. (1990). The Fifth Discipline (re-print 1992). London, Century Business.
Zollo, M., \& Winter, S. G. (2002). Deliberate learning and the evolution of dynamic capabilities. Organization science, 13(3), 339-351. 